\title{
Visual Treatment Objective: A Review
}

\author{
Mounika Deva, Vasu Murthy Sesham \\ Department of Orthodontics, Kamineni Institute of Dental Sciences, Narketpally, Nalgonda, Telangana, India
}

Email for correspondences: mounika.deva01@gmail.com

\begin{abstract}
A visual treatment objective (VTO) is like a "blueprint" used in building a house. It helps to forecast the normal growth of the patient and the anticipated influences of treatment. The VTO permits the development of alternative treatment plans. Orthodontists can plan the treatment of skeletal discrepancies in their attempt to achieve a more stable and pleasing result. The VTO forecast is valuable for the orthodontist's self-improvement in that it permits to set goals in advance and compare them with the results at the end of treatment. Identification of the discrepancies between goals and results provides the orthodontist with an objective picture of the areas in which his treatment could be improved. The purpose of this review is to present the commonly used methods of cephalometric VTO published in literature till date.
\end{abstract}

Key words: Holdaway's visual treatment objective, Rickett's visual treatment objective, visualized treatment objective

\section{INTRODUCTION}

The amount and direction of facial growth have long been regarded as vital factors in determining the success or failure of orthodontic treatment in a large percentage of patients. ${ }^{[1-4]}$ The prediction has always been a part of science. The ability to predict craniofacial growth accurately for individual cases will significantly reduce the difficulty of treatment planning in many instances. ${ }^{[3,5]}$ For predicting growth in orthodontic patients, many clinicians have advocated the use of a "growth forecast" or a "treatment objective" as a target toward which to work during treatment. ${ }^{[6]}$

Baumrind suggested that the ability to predict assists the orthodontist psychologically in the treatment planning process by removing some of the art and adding a little more science. In orthodontic patients, the ability to predict is important; however, due to the variation in patient's growth

\begin{tabular}{|c|c|}
\hline Quick Response Code & Article Info: \\
\hline & doi: 10.5866/2018.10.10136 \\
\hline & Received: $23-06-2018$ \\
\hline & Revised: 23-07-2018 \\
\hline & Accepted: $18-08-2018$ \\
\hline & Available Online: 25-09-2018 (www. \\
\hline & nacd.in)C NAW, zU18 - All rights reserved \\
\hline
\end{tabular}

and development, achieving results of treatment prediction are difficult. ${ }^{[7]}$

The term visual treatment objective (VTO) which stands for visualized treatment objective was first coined by Holdaway but used extensively by Dr. Ricketts. The term VTO was coined to communicate the planning of treatment for any orthodontic problem. After setting up the teeth ideally within the anticipated or "grown" facial pattern, the orthodontist must decide how far he must go with mechanics and orthopedics to achieve his goals, whether it is possible to achieve them, and what the alternatives are. Identification of the discrepancies between goals and results provides the orthodontist with an objective picture of the areas in which his treatment could be improved. ${ }^{[8]}$ It has been established that good facial growth and a good orthodontic outcome are correlated; hence, the ability to assess and predict facial growth cephalometrically is important to orthodontists, and to better plan treatment and achieve stable and esthetic outcomes. Several methods of prediction using lateral cephalograms have been attempted and established, and many have been made available to clinicians.

\section{DEFINITIONS}

- A VTO is a cephalometric tracing representing the changes that are expected during treatment (Proffit). 
- VTO is a visual plan to forecast the normal growth of the patient and anticipated influences of treatment, to establish individual objectives that are to be achieved for that patient (Ricketts)

\section{ORIGIN OF VTO}

VTOs of craniofacial growth have been proposed by various authors and these include Holdaway, Ricketts, and Jacobson and Sadowsky method analyses among others.

Ricketts (1960) stated that all treatment planning constituted some type of the prediction of craniofacial growth and tooth movement and termed this method of prediction as a dynamic synthesis. Treatment for a growing patient according to the Ricketts must be planned and directed to the face and structure that can be anticipated in future and not to the skeletal structure that the patient presents initially. The treatment plan should take advantage of the beneficial aspects of growth and minimize any undesirable effects of growth possible. Treatment designs incorporating growth effects had proven to be quite appropriate and indeed could be recommended at a clinical level for the establishment of objectives and the planning of Anchorage. ${ }^{[9]}$

Dr. Reed A. Holdaway picked the idea of Ricketts and devised the term "visualized treatment objective" which was descriptive of the application, existing morphology, and expected growth in modular increments which provided a reference base. The requirements of individual patient, in terms of objectives and required tooth movement were also considered. Desired changes in anterior teeth could be followed by the setup of the molars, depending on the needs and estimates of anchorage and arch form change.

Bench et al. stated that VTO permits the development of alternative treatment plans. They also stated that after setting up the teeth ideally within the anticipated/growth facial pattern, the orthodontist must decide how far he must go with mechanics and orthopedics to achieve them, whether it is possible to achieve them and what are the other alternatives. ${ }^{[10]}$

Steyn (1979) devised his own VTO based on South African Caucasian sample and described some norms. His VTO uses the sella-nasion (S-N) and basion-nasion (Ba-Na) planes and is gender specific. He allocated different increments of growth, in certain areas, for males and females. The lower incisor is positioned according to A-pogonion (Apo), and then, the upper incisor is positioned relative to lower incisor.

Jacobson and Sadowsky (1980) devised a soft tissue template to help in constructing the soft tissue outline. ${ }^{[11]}$ As with the Holdaway VTO, the upper incisor is positioned after the soft tissue has been constructed. Magness (1987) proposed a miniVTO to predict the incisor and molar relations on the basis of growth and treatment changes to the dentoskeletal framework. ${ }^{[12]}$

\section{ADVANTAGES OF VTO}

Jacobson and Sadowsky have outlined the accomplishments of VTO as follows: [11]

1. Predicts growth over an estimated treatment time, based on the individual morphogenetic pattern.

2. Analyzes the soft tissue facial profile.

3. Graphically plans the best soft tissue facial profile for the particular patient.

4. Determines favorable incisor repositioning, based on an "ideal" projected soft tissue facial profile.

5. Assists in determining total arch length discrepancy when taking into account "cephalometric correction."

6. Aids in determining between extraction and non-extraction treatment.

7. Aids in deciding which teeth to extract, if extractions are indicated.

8. Assists in planning treatment mechanics.

9. Assists in deciding which cases are more suited to surgical and/or surgical- orthodontic correction.

10. It provides a visual goal or objective for which to strive during treatment.

\section{Other Advantages of the VTO}

Other advantages of the VTO are as follows:

1. Establishment of specific treatment goals.

2. Formulation of specific treatment plan to reach treatment goals.

3. Assistance in making midtreatment correction.

4. Assistance in determining if an ideal treatment result is attainable orthodontically/surgically.

5. Enhancing communication between patients and clinicians.

6. Allowing quantification of proposed movements to reduce the difficulties in planning a facial response to different movements. 
7. Allowing rapid comparisons of different treatment options before arriving at a final treatment plan.

\section{Limitations of VTO}

Despite the listed advantages of VTO, limitations exist in their implementation:

1. Use of average growth increments in growth prediction.

2. Use of existing morphological traits to predict future growth events.

3. Failure of presenting VTO analyses as an exact representation of treatment outcome

\section{DESCRIPTION OF VTOS}

a) Rickett's VTO

Ricketts (1957) proposed a method using cephalometric radiography in which craniofacial growth and orthodontic treatment effects were predicted. Rickett's treatment prediction was based on the reaction of the skeletal elements and the teeth to orthodontic treatment. He claimed that his technique "appeared to be sensibly accurate in more than $90 \%$ of routine clinical cases to date."[5] In 1960, Ricketts emphasized that since all treatment planning constituted some type of prediction estimating the amount of change that would occur, it should include both the prediction changes due to tooth movement and that of facial changes. Ricketts called this method of prediction a "dynamic synthesis" in which craniofacial growth and tooth movement were predicted. ${ }^{[13]}$ Ricketts et al constructed VTO based on positioning of the teeth. Lower incisor was placed first in the preconceived ideal relations and depended on the soft tissue to drape over these new tooth positions in a harmonious relation. They put their approach very succinctly and aptly as "begin with the end in mind."[14]

b) Holdaway's VTO

Holdaway's goal of his "dynamic" cephalometric analysis and prediction was to establish a balanced facial profile with pleasing facial esthetics and to evaluate the orthodontic correction necessary to obtain the latter goals. The main difference between Holdaway's VTO and other types was that Holdaway predicted the soft tissue profile first then positioned the maxillary incisors accordingly. ${ }^{[15,16]}$ In contrast to Ricketts, Holdaway believed that the mandibular incisor could not be rigidly fixed to any anatomical landmark such as the APo line. Instead, the mandibular incisors should be placed relative to the maxillary incisors where adequate lip support had been established.

\section{RICKETT'S VTO ${ }^{[5,8]}$}

Ricketts constructed VTO based on specific areas. According to Ricketts, growth changes of the craniofacial complex should be studied by keeping the center of least growth as a registration point. From various studies, Ricketts found that the center of least growth is near the pterygomaxillary fissure because growth changes occur in a radial manner from this area while the area itself remains constant. A point called the "cc point" at intersection of $\mathrm{Ba}-\mathrm{Na}$ line to facial axis was constructed, and then, superimpositions were done on the Ba-N plane registered at cc point. Six areas of prediction were described:

1. Cranial base prediction

2. Mandibular growth prediction

3. Maxillary growth prediction

4. Occlusal plane position

5. Location of the dentition

6. Soft tissue of the face

\section{Cranial Base Prediction}

The tracing paper is placed over the original tracing. Starting at the $\mathrm{CC}$ point, $\mathrm{Ba}-\mathrm{Na}$ line is traced. The Ba-Na is grown $1 \mathrm{~mm} /$ year for 2 years (estimated treatment time). The tracing is slided

back to coincide with the new and old nasion to trace nasion area, and similarly, the basion area is traced [Figure 1].

\section{Mandibular Growth Prediction}

The mandibular angle changes for every treatment procedure. It is calculated as the degree

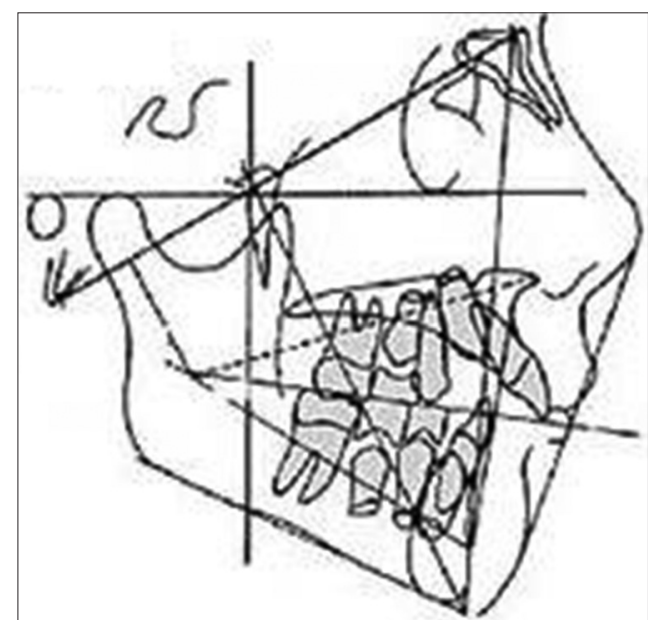

Figure 1: Steps in Rickett's visual treatment objective 
of opening or closing of facial axis. The facial axis opens 1 with growth. The following are the changes in the facial axis:

1. Convexity reduction - facial axis open $1^{\circ}$ for $5 \mathrm{~mm}$.

2. Molar correction - facial axis open by $1^{\circ}$ for $3 \mathrm{~mm}$.

3. Overbite correction - facial axis open $1^{\circ}$ for $4 \mathrm{~mm}$.

4. Crossbite correction - facial axis open by $1-1 \frac{1}{2} 2^{\circ}$ recovers half the distance. The facial axis may close as with the use of high pull headgear or due to extraction.

5. For facial patterns - for every standard deviation on the dolichofacial pattern side, it opens by $1^{\circ}$. Moreover, for every standard deviation toward the brachyfacial side, it tends to close $1^{\circ}$.

The DC point is marked, superimposed at basion point on the Ba-N plane. Using DC point as the fulcrum, tracing is rotated up at nasion to open the bite and rotated down to close the bite [Figure 2].

\section{Condylar axis and corpus axis growth}

The condylar axis, coronoid process, and condyle are traced. On the condylar axis, $1 \mathrm{~mm} /$ year down from point DC is marked and slided up to the Ba-N line. The condylar axis is extended to the $\mathrm{Xi}$ point, locating a new Xi point. With the old and new Xi points coinciding, corpus axis is traced, extending it $2 \mathrm{~mm} /$ year forward of the old PM point (PM point moves forward $2 \mathrm{~mm} /$ year in normal growth) [Figure 3].

\section{Symphysis construction}

Tracing is slided back along the corpus axis superimposing the new and old PM points to trace the symphysis and mandibular plane. The facial plane is constructed from new NA to $\mathrm{PO}$ and a facial axis from CC to $\mathrm{Gn}$ (where the facial plane and mandibular plane cross) [Figure 4].

\section{Maxillary Growth Prediction}

To locate the new maxilla within the face, tracing is superimposed at nasion along the facial plane, and the distance between the original and new menton is divided into thirds by drawing two marks (1 and 2$)$. To outline the body of maxilla, mark ${ }^{\#} 1$ (superior mark) is superimposed on the original menton along the facial plane and the palate is traced (with exception of point A) [Figure 5].

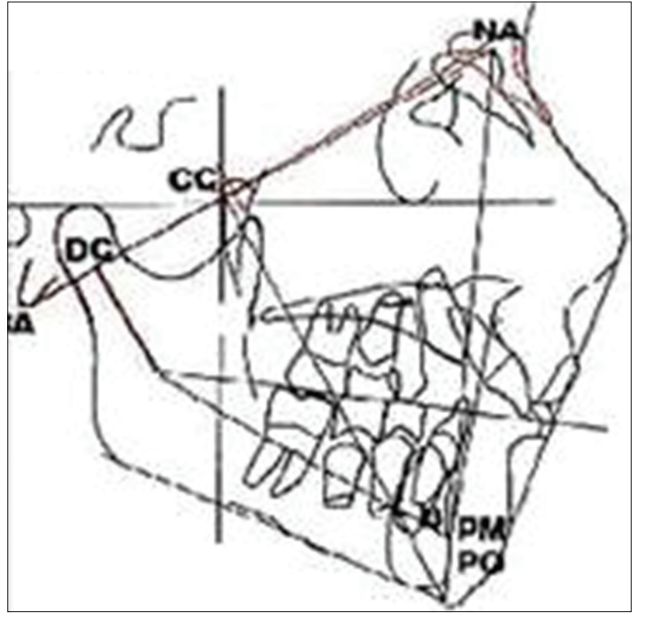

Figure 2: Steps in Rickett's visual treatment objective

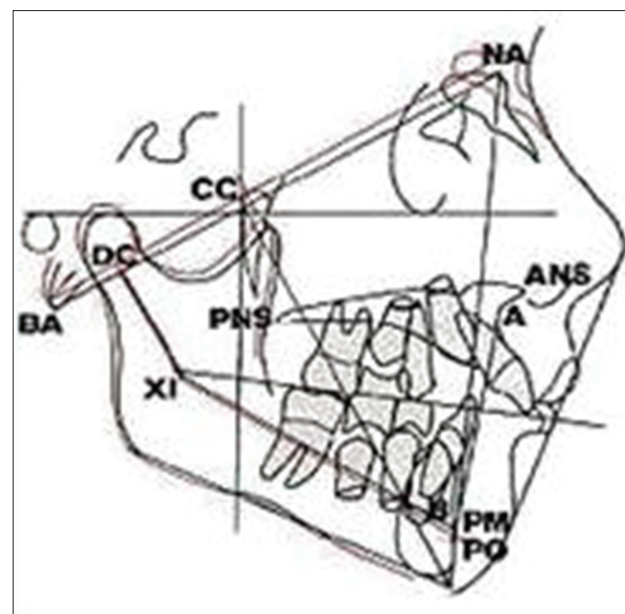

Figure 3: Steps in Rickett's visual treatment objective

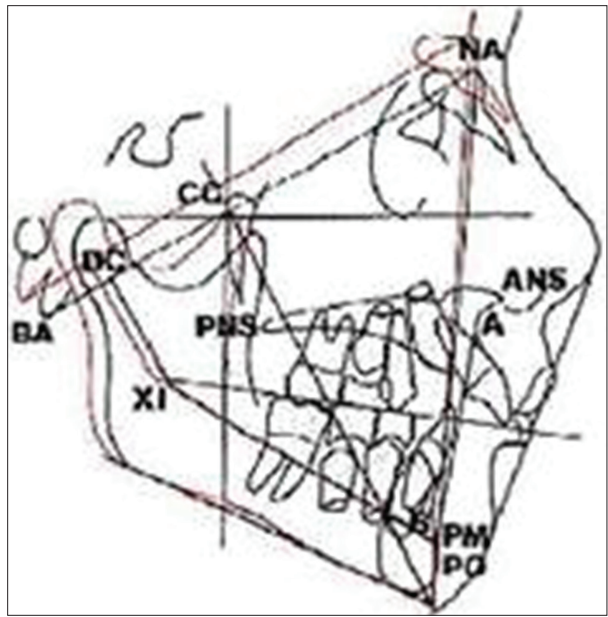

Figure 4: Steps in Rickett's visual treatment objective 


\section{Point A changes related to Ba-Na}

- Point A changes with various mechanics (maximum change).

\begin{tabular}{ll}
\hline Mechanics & Maximum range \\
\hline Headgear & $8 \mathrm{~mm}$ \\
Class II elastics & $3 \mathrm{~mm}$ \\
Activator & $2 \mathrm{~mm}$ \\
Torque & $1-2 \mathrm{~mm}$ \\
Class III elastics & $2-3 \mathrm{~mm}$ \\
Face mask & $2-4 \mathrm{~mm}$ \\
\hline
\end{tabular}

\section{Occlusal Plane Position}

Mark ${ }^{\# 2}$ is superimposed on original menton and facial plane and then parallel mandibular planes rotating at menton and occlusal plane is constructed [Figure 6].

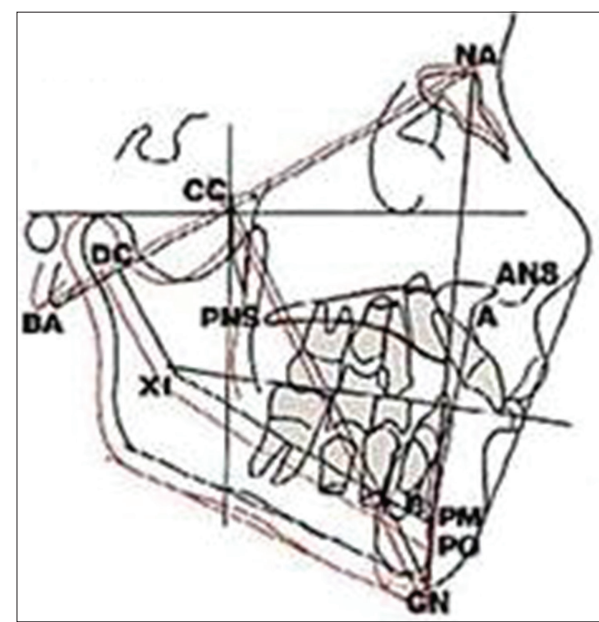

Figure 5: Steps in Rickett's visual treatment objective

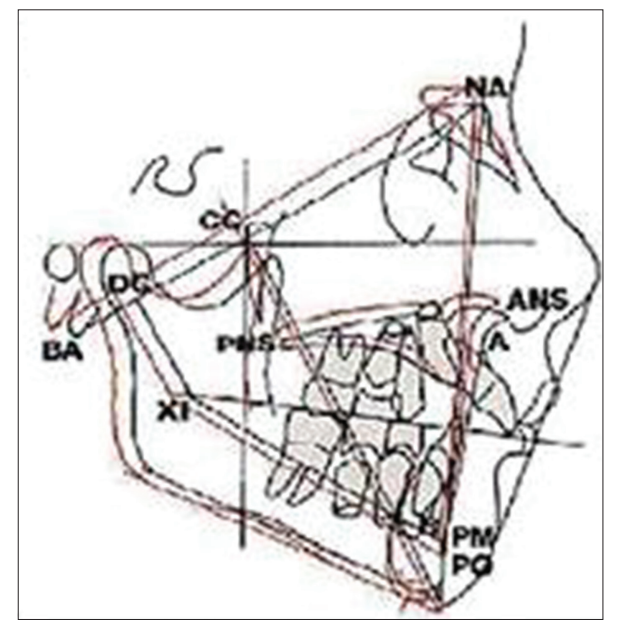

Figure 6: Steps in Rickett's visual treatment objective

\section{Dentition: Lower Incisor}

It is placed in relation to the symphysis of the mandible, the occlusal plane, and the APo plane. Superimposed on the corpus axis at PM, a dot is placed representing the tip of the lower incisor ideal position which is $1 \mathrm{~mm}$ above the occlusal plane and $1 \mathrm{~mm}$ in front of the APo plane [Figure 7].

\section{Lower molar}

Without treatment, the lower molars will erupt directly upward to the new occlusal plane. With treatment, $1 \mathrm{~mm}$ of molar movement equals $2 \mathrm{~mm}$ of arch length [Figure 8].

\section{Upper molar}

The upper molar is traced in good Class I relationship to the lower molar.

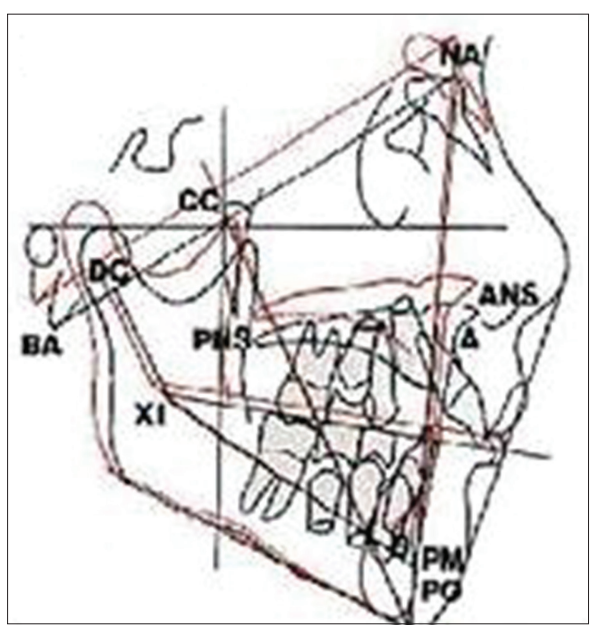

Figure 7: Steps in Rickett's visual treatment objective

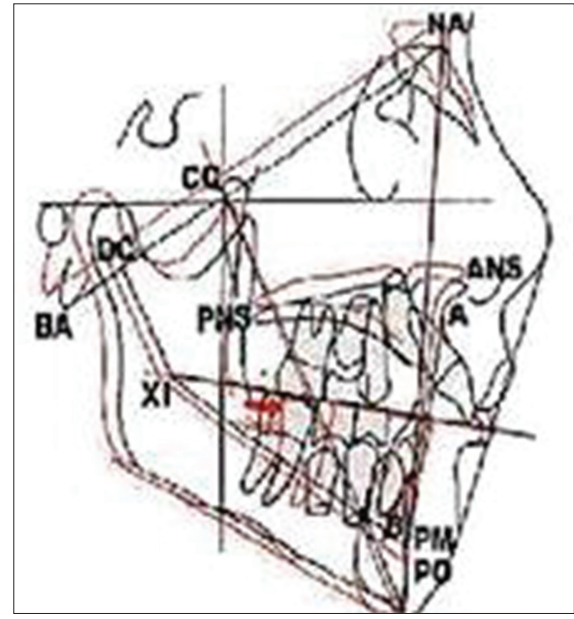

Figure 8: Steps in Rickett's visual treatment objective 


\section{Upper incisors}

The upper incisors are placed in a good overbite and overjet position $(2.5 \mathrm{~mm})$ with an interincisal angle of 130 [Figure 9].

\section{Soft Tissues}

\section{Nose}

Superimposed at nasion along facial plane and palatal plane, the prediction is moved back $1 \mathrm{~mm} /$ year along the palatal plane, and the tip of the nose is traced fading into bridge [Figure 10].

\section{Point A, upper lip}

Superimposition is done along the facial plane at occlusal plane. The horizontal distance between the original and new upper incisor tips is divided into thirds using two marks (1 and 2). Soft tissue thickness of upper lip does not change, so by superimposing old and new point, soft tissue

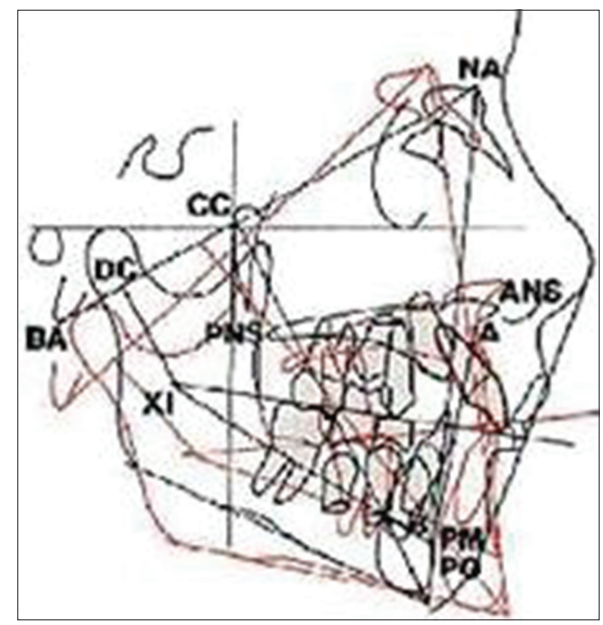

Figure 9: Steps in Rickett's visual treatment objective

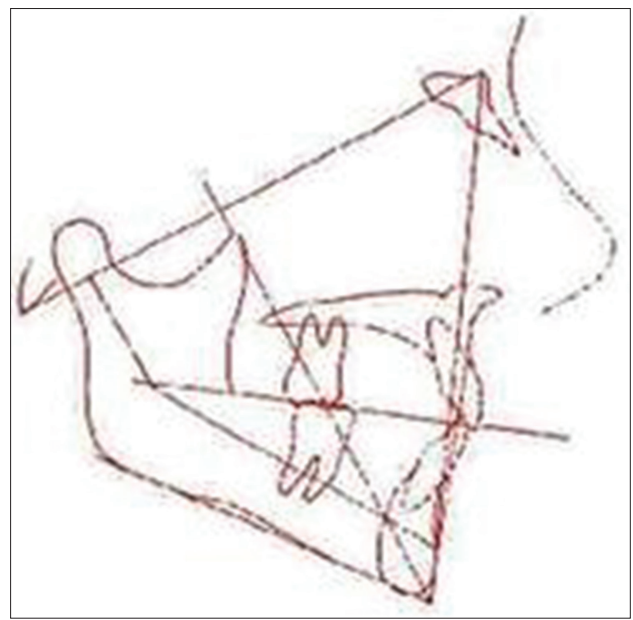

Figure 10: Steps in Rickett's visual treatment objective point A is traced. Upper lip tracing is done by superimposing the tip of upper incisor on mark 1 parallel to the occlusal plane. The upper lip is traced connecting with soft tissue point " $\mathrm{A}$ " [Figure 11].

\section{Point B, lower lip}

The overjet and overbite of the original tracing are bisected and points are marked. Superimpose interincisal points keeping occlusal planes parallel and trace lower lip and soft tissue B point.

\section{Completed VTO [Figure 12]}

The completed VTO is superimposed in five areas to establish individual objectives for a particular case. The five superimposition areas used to evaluate the face are in the following order: The chin, maxilla, teeth in the mandible, teeth in the maxilla, and facial profile [Figure 13].

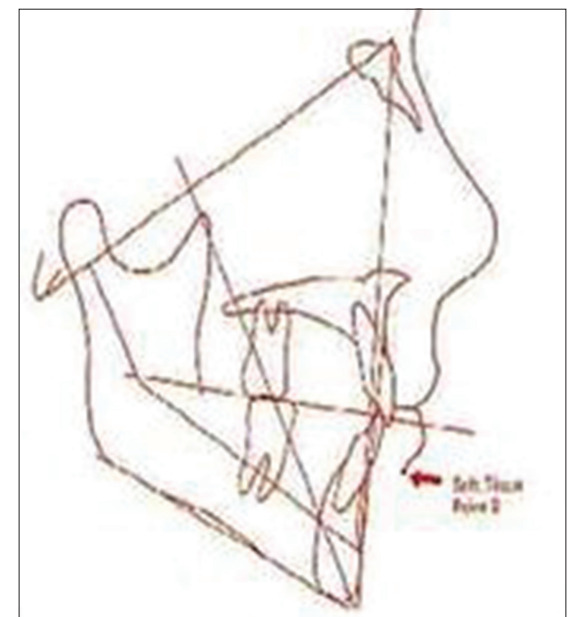

Figure 11: Steps in Rickett's visual treatment objective

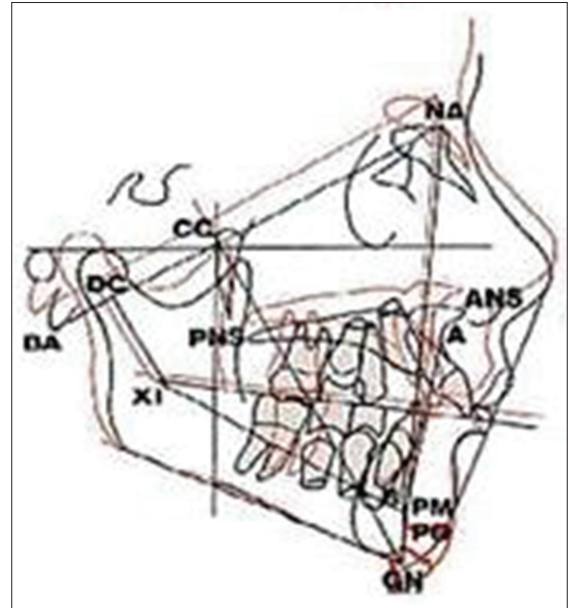

Figure 12: Steps in Rickett's visual treatment objective 


\section{Superimposition Area 1 (Ba-Na at CC Point)}

Evaluation area 1 is the amount of growth of the chin in millimeters. It denotes the change in chin in an opening or closing direction that may result from mechanics and any change in upper molar. In normal growth, the chin grows down the facial axis and 6-year molars also grow down the facial axis.

\section{Superimposition Area 2 (Ba-Na at Nasion)}

Evaluation area 2 shows a change in the maxilla (Point A). The basion-nasion-point A angle does not change in normal growth. Therefore, any change in this angle would be due to the effect of the mechanics

\section{Superimposition Area 3 (Corpus Axis at PM)}

It evaluates any changes that take place in the mandibular denture. In normal growth, the lower denture remains constant with the APo plane (the denture plane). Evaluation area 3 describes whether to intrude, extrude, advance, or retract the lower incisors. Evaluation area 4 describes the lower molars to determine the need and whether to upright or hold the lower molars.

\section{Superimposition Area 4 (Palate at ANS)}

It evaluates any changes that take place in the maxillary denture. In normal growth, upper molars and upper incisors grow on their polar axis. In evaluation area 5 , we evaluate the upper molars whether to hold, intrude, extrude, distalize, or bring forward. In evaluation area 6 , we evaluate the upper incisors to intrude, extrude, retract, advance, torque, or tip them.

\section{Superimposition Area 5 (Esthetic Plane at the crossing of the Occlusal Plane)}

Evaluation area 7 describes the changes in soft tissue profile. In normal growth, the face becomes less protrusive with reference to the esthetic plane.

\section{HOLDAWAY'S VTO ${ }^{[16]}$}

Holdaway's VTO has 12 sequential steps. Plane of reference is SN plane.

\section{Step I}

A clean sheet of tracing material is placed over the original tracing, copying (1) the frontonasal area, both hard and soft tissues with the soft tissue nose carried down to near the point where the outline of the nose starts to change directions; (2) the S-N line; and (3) the nasion-point A line [Figure 14].

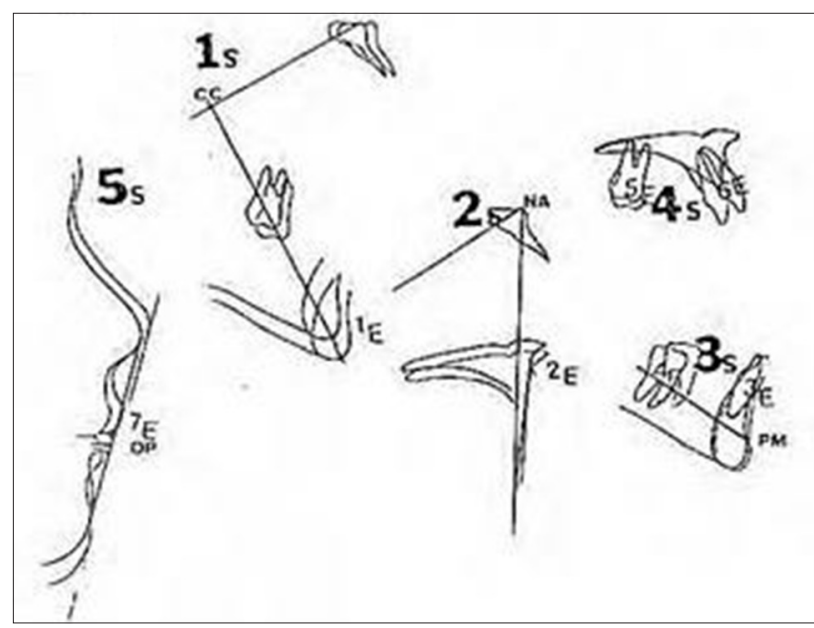

Figure 13: Superimposition areas in Rickett's visual treatment objective

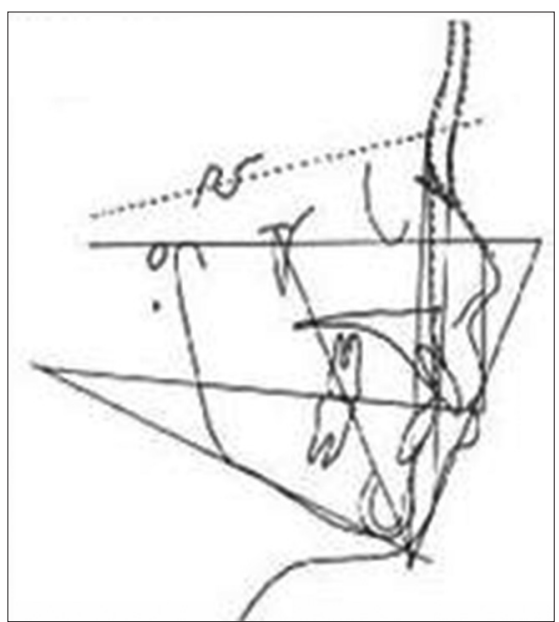

Figure 14: Steps in Holdaway's visual treatment objective

\section{Step II}

First, the SN line is superimposed and the tracing is moved to show expected growth $(0.66-0.75 \mathrm{~mm} /$ year, unless a pubertal growth spurt is expected from wrist plate studies). Second, the outline of sella is traced. Third, facial axis (Rickett's foramen rotundum to gnathion) is either copied or changed as expected to behave according to the facial type of the patient, and the treatment mechanics customarily used in such cases. (The facial axis line is usually opened about 1 , but it may even be closed if one is confident that mandibular growth of the forward rotational type will occur during treatment) [Figure 15]. 


\section{Step III: Vertical Growth of Mandible, Determining Anterior Facial Height}

The VTO facial axis should be superimposed on the original and the VTO is moved up so that the VTO SN line is above the original SN. The amount of movement will usually be $3 \mathrm{~mm} /$ year of growth, except in accelerated growth spurt periods. Second, the anterior portion of the mandible is copied, including the symphysis and anterior half of the lower border. Furthermore, the soft tissue chin is drawn, eliminating any hypertonicity evident in the mentalis area. Third, the Downs mandibular plane is copied [Figure 16].

\section{STEP IV: ANTEROPOSTERIOR GROWTH OF THE MANDIBLE, DETERMINING THE POSTERIOR BORDER}

Superimposition is done on the mandibular plane, and the VTO is moved forward until the original sella and the VTO sella are in a vertical relation. Next, with the tracing in this position, the gonial angle, the posterior border, and the ramus are copied. Finally, superimposition is done on sella to complete the condyle. (Note: One should not open the facial axis $>1^{\circ}-2^{\circ}$ because greater opening than this is usually inconsistent with good treatment mechanics) [Figure 17].

\section{Step V: Maxilla and Lower Nose}

The VTO NA line is superimposed on the original NA line, and the VTO should be moved up until $40 \%$ of the total growth is expressed above the SN line and $60 \%$ below the mandible. Second, with the tracing in this position, the maxilla is copied to include the posterior two-thirds of the hard palate, PNS to ANS to $3 \mathrm{~mm}$ below ANS. Third, also with the tracing in this same position, the nose outline is completed around the tip to the middle of the inferior surface [Figure 18].

\section{Step VI: Occlusal Plane}

With the VTO still superimposed on the line NA, the VTO is moved so that vertical growth between the maxilla and the mandible is expressed 50\% above the maxilla and 50\% below the mandible. Second, with the tracing in this position, the occlusal plane is copied $3 \mathrm{~mm}$ above the lip embrasure [Figure 19].

\section{Step VII: Lip Contour}

The harmony line is drawn tangent to lower chin. Upper sulcus depth has average range of $3-7 \mathrm{~mm}$,

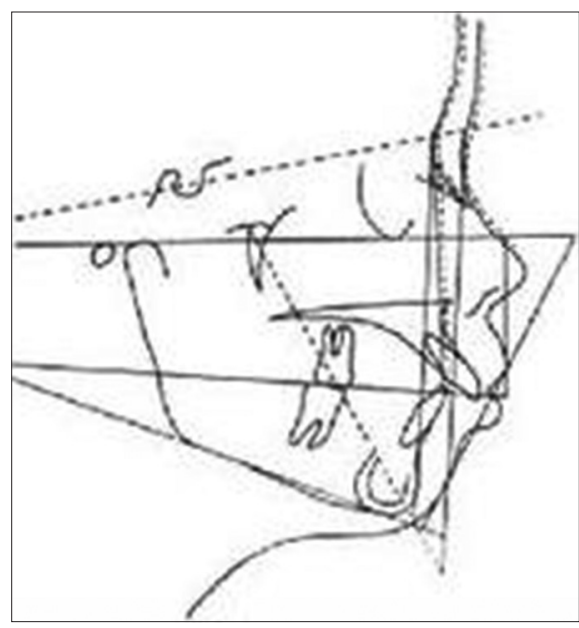

Figure 15: Steps in Holdaway's visual treatment objective

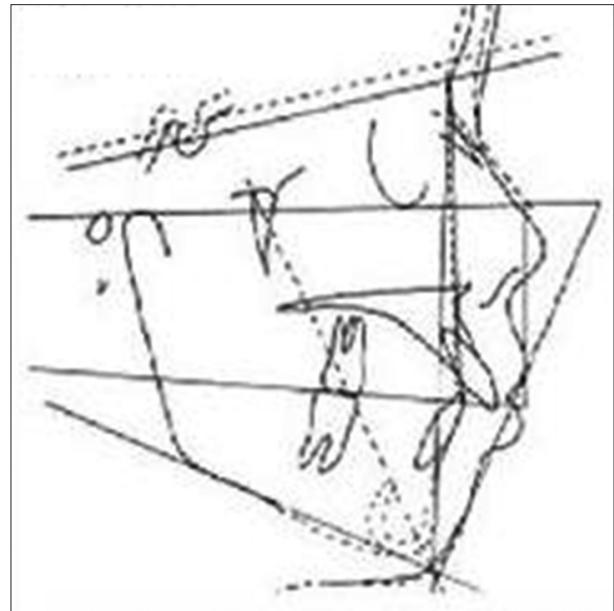

Figure 16: Steps in Holdaway's visual treatment objective

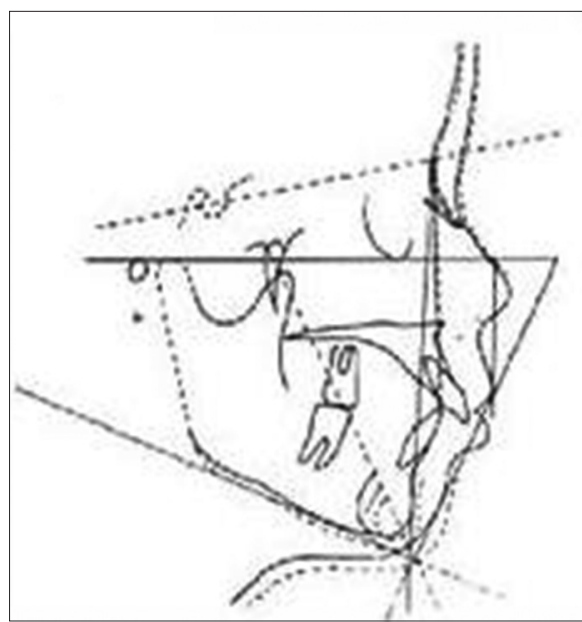

Figure 17: Steps in Holdaway's visual treatment objective 
with a mean of $5 \mathrm{~mm}$. The angle of harmony line is adjusted so that the upper sulcus depth is $3-3.5 \mathrm{~mm}$. Superimposition is made on the maxilla, NA line, and occlusal plane; upper lip is drawn. To draw the upper lip, a template can be used. The lower lip is drawn touching the lower lip or $1 \mathrm{~mm}$ in front of it. Lip template by Jacobson and Sadowsky can be used to decide the lip contour [Figure 20].

\section{Step VIII: Upper Incisor Position}

The upper incisor position is determined by (a) lip strain, (b) upper lip change, and (c) maxillary incisor rebound. Lip strain is measured as the difference between basic upper lip thickness and thickness of the vermillion border. The change in the position of upper lip is calculated from

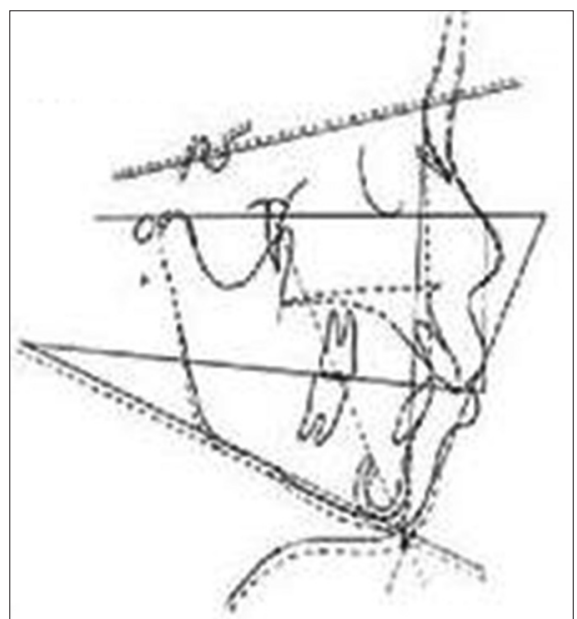

Figure 18: Steps in Holdaway's visual treatment objective

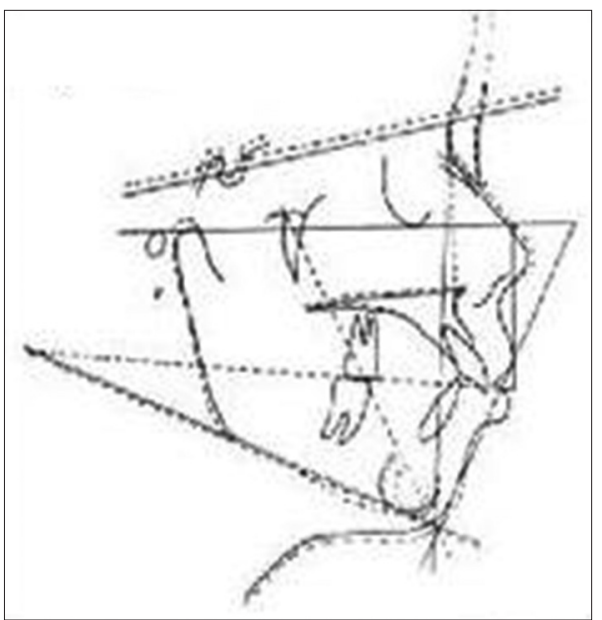

Figure 19: Steps in Holdaway's visual treatment objective pre-treatment to VTO. There may be a rebound tendency for maxillary incisor by $1.5 \mathrm{~m}$; it is added to the previous measurement.

The superimposition is again carried out on the NA line and maxilla, and then, maxillary incisor is drawn taking into account, the above-mentioned criteria, namely change in axial inclination of upper incisor and relation of upper incisor with occlusal plane [Figure 21].

\section{Step IX: Lower Incisor Position}

Lower incisor is drawn in harmonious relation to upper incisor with superimposition on the mandibular plane and symphysis with occlusal plane as the guide. The lower incisor is tipped back about the apex unless bodily movement is desired. The

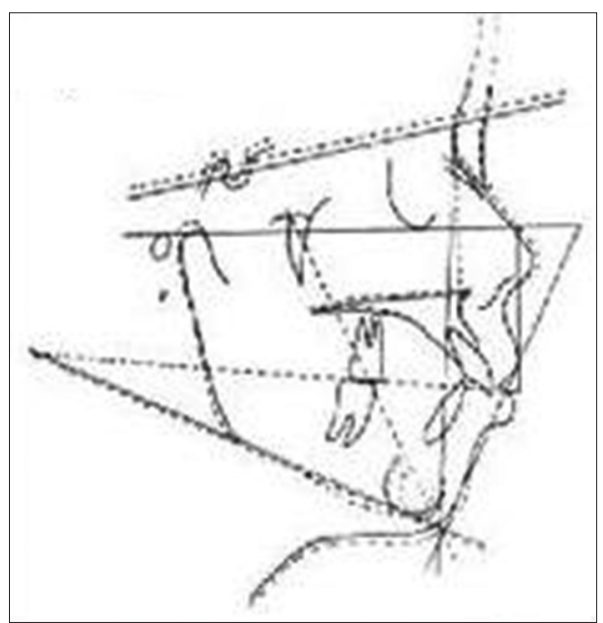

Figure 20: Steps in Holdaway's visual treatment objective

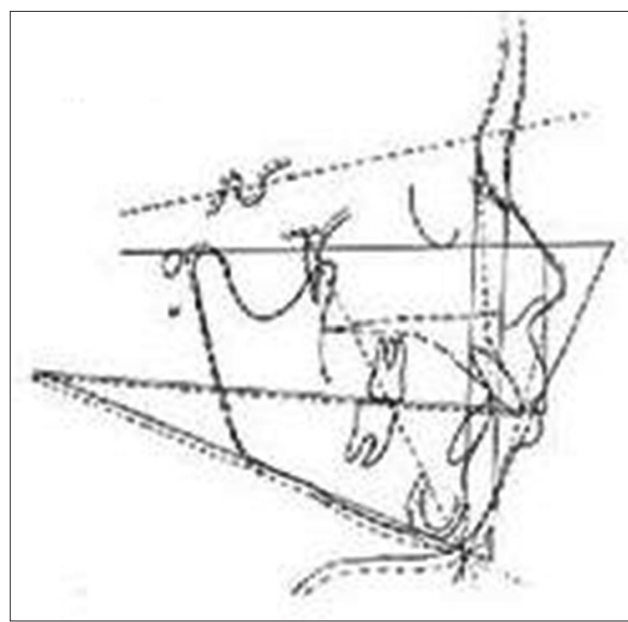

Figure 21: Steps in Holdaway's visual treatment objective 


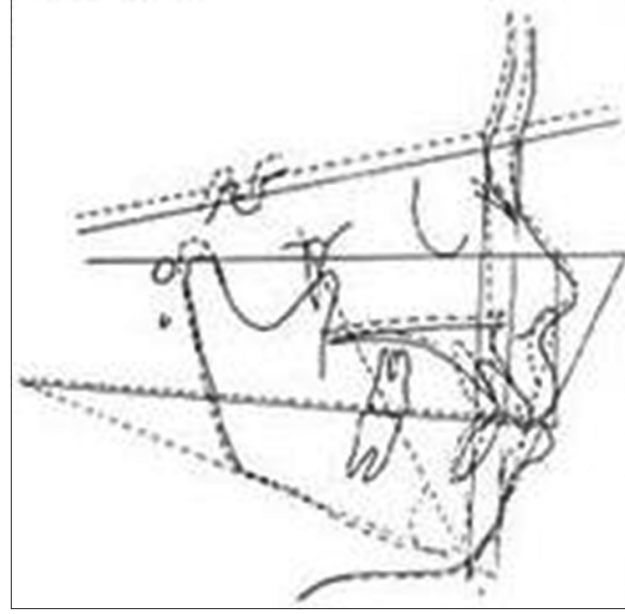

Figure 22: Steps in Holdaway's visual treatment objective

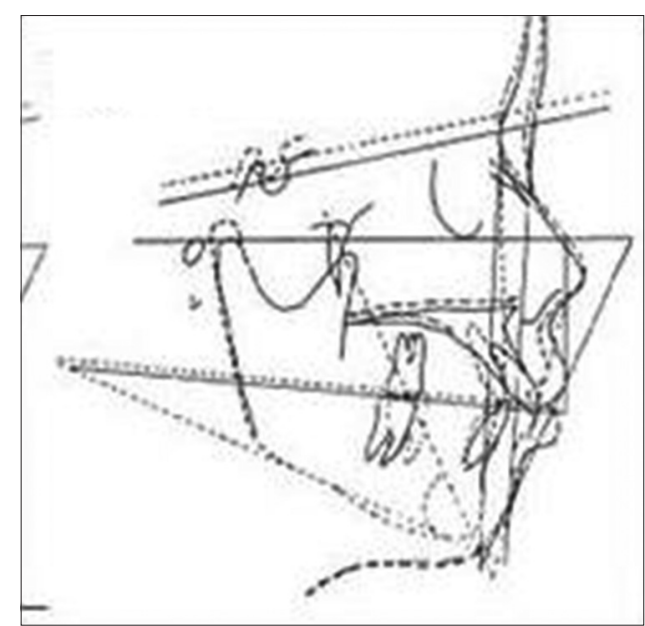

Figure 23: Steps in Holdaway's visual treatment objective

number of millimeters of lower incisor movement is noted and discrepancy is calculated. To find the arch length loss, the value is multiplied by two and the amount of crowding is added [Figure 22].

Total discrepancy $=(2$ lower incisor movement $)$ + crowding (calculated by model analysis).

\section{Step X: Lower Molar Position}

In extraction cases, lower molar is moved forward for the remaining amount. In minimum discrepancy cases, lower molar is tipped back to find out whether non-extraction treatment can be done [Figure 23].

\section{Step XI: Upper Molar Position}

With occlusal plane and lower molar as a guide, upper molar is drawn in Class 1 relation

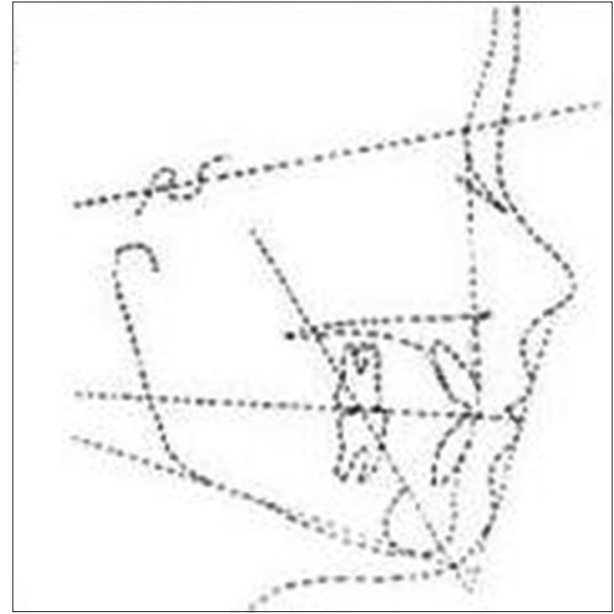

Figure 24: Steps in Holdaway's visual treatment objective

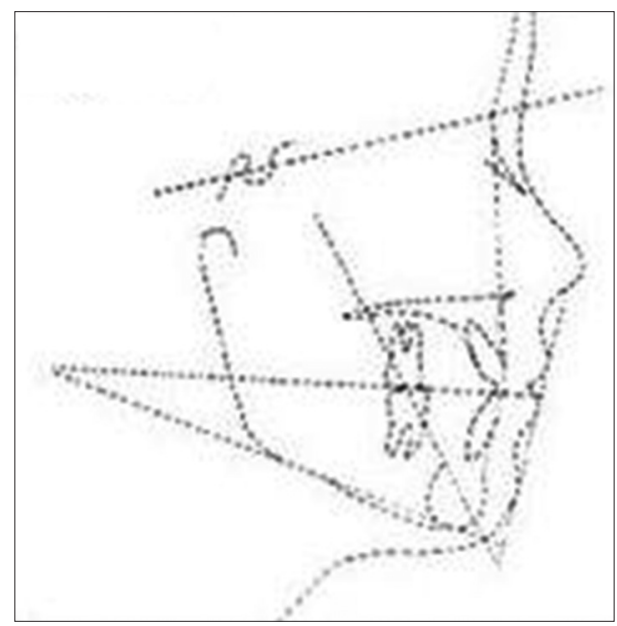

Figure 25: Steps in Holdaway's visual treatment objective

to lower molar. Amount of upper molar movement is calculated by keeping the original NA line and maxilla as a guide [Figure 24].

\section{Step XII: Point A}

The position of point $\mathrm{A}$ is assessed by the best fit of the maxilla. Change in position will be drastic for bodily movement of upper incisor and orthopedic appliances. The change in the position of point $A$ is analyzed and drawn [Figure 25].

\section{CONCLUSION}

The predetermination of the eventual outcome of orthodontic treatment should be a part of each orthodontist's armamentarium. The visualized treatment objective, or VTO, acts as a vehicle 
making changes only to the point where the best possible soft tissue profile is established and then compute the tooth movement necessary to develop ideal profile relationships. For patients in whom growth is expected, forecasting growth with a visual treatment plan with the input of soft tissue visualization will be useful. However, we should not forget that every individual is unique in his own aspect, and therefore, we should not jump to conclusions but study our patient's overtime and treat them to their individual requirements.

\section{REFERENCES}

1. Bjork A. The significance of growth changes in facial pattern and their relationship to changes in occlusion. Dent Rec (London) 1951;71:197-208.

2. Downs WB. Variations in facial relationships; their significance in treatment and prognosis. Am J Orthod 1948;34:812-40.

3. Brodie AG, Downs WB, Goldstein A, Myer E. Cephalometric appraisal of orthodontic results: A preliminary report. Angle Orthod 1938;8:261-5.

4. Bjork A, Skieller V. Facial development and tooth eruption. Am J Orthod 1972;62:339-82.

5. Ricketts RM. Planning treatment on the basis of the facial pattern and an estimate of its growth. Angle Orthod 1957;27:14-37.
6. Hirschfeld W, Moyers R. Prediction of craniofacial growth: The state of the art. Am J Orthod 1975;67:243-52.

7. Bishara SE. Facial and dental changes in adolescents and their clinical implications. Angle Orthod 2000;70:471-83.

8. Bench RW, Gugino CF, Hilgers JJ. Bio-progressive therapy, part 3: Visual treatment objective or vto. J Clin Orthod 1977;11:744-63.

9. Ricketts RM. The influence of orthodontic treatment on facial growth and development. Angle Orthod 1996;30:103-33.

10. Bench RW, Gugino CF, Hilgers JJ. Bio-progressive therapy, Part 2: Principles of bioprogressive therapy. J Clin Orthod 1977;11:661-82.

11. Jacobson A, Sadowsky PL. A visualized treatment objective. J Clin Orthod 1980;14:554-71.

12. Magness WB. The mini-visualized treatment objective. Am J Orthod Dentofacial Orthop 1987;91:361-74.

13. Ricketts RM. Influence of orthodontic treatment on facial growth and development. Angle Orthod 1960;30:103-33.

14. Ricketts RM, Roth RH, Chaconas SJ, Schulhoff RJ, Engel GA. Orthodontic diagnosis and Planning. United States: Rocky Mountain Orthodontics; 1982.

15. Holdaway RA. A soft-tissue cephalometric analysis and its use in orthodontic treatment planning. Part I. Am J Orthod 1983;84:1-28.

16. Holdaway RA. A soft-tissue cephalometric analysis and its use in orthodontic treatment planning. Part II. Am J Orthod 1984;85:279-93. 